\title{
HEAT REQUIREMENTS AS A TOOL FOR PREDICTING THE ANNUAL GENERATIONS OF CERTAIN PIERCING-SUCKING INSECT PESTS INFESTING COWPEA PLANTS AT MANSOURA DISTRICT. \author{
Hala A. K. El-Serafi' and Eman A. S. Abd El-Halim 'r \\ 1- Economic Entomology Dept., Fac. of Agric., Mansoura Univ., Egypt.
} \\ Ghanim, A. A.' ; A. M. A. Abu El-Naga'; M. E. El-Naggar'; 2- Plant Protection Res. Institute, Agric. Res. Center, Dokki Giza, Egypt.
}

\begin{abstract}
Laboratory experiments were conducted in the laboratory of Economic Entomology Department, Faculty of Agriculture, Mansoura University to estimate the heat requirements as a tool for predicting the annual generation of Aphis craccivora Koch. and Nezara viridula (L.) attacking cowpea plants at Mansoura district. The obtained results revealed that the required time for developing nymphal instars of $A$. craccivora decreased as the temperature increased when this insect reared on cowpea plants.

The results assured that, the developmental rate declined as temperature increased with significant differences between developmental rates for $A$. craccivora. The lower development threshold for the nymphal stage was 7.69, and the thermal units expressed as degree-days (dd's) required for nymphal stage were 118.30 ; $121.26 ; 112.69 ; 118.09$ and 122.22 (dd's) at $15^{\circ} \mathrm{C} ; 20^{\circ} \mathrm{C} ; 25^{\circ} \mathrm{C} ; 30^{\circ} \mathrm{C}$ and $35^{\circ} \mathrm{C}$ respectively. The obtained results showed that the lower threshold of development for the adult stage of $A$. craccivora was $15^{\circ} \mathrm{C}$. The thermal units required for various development recorded 127.68, 154.76; 184.24, 206.64 and 213.12 (dd's) at $15^{\circ} \mathrm{C}, 20$ ${ }^{\circ} \mathrm{C}, 25^{\circ} \mathrm{C}, 30^{\circ} \mathrm{C} 35$ respectively.

The results indicated that the lower development threshold $\left(t_{0}\right)$ for the incubation periods of $N$. viridula (L.) was $35^{\circ} \mathrm{C}$ when reared on cowpea plants. The results revealed that the thermal units expressed as degree-days (dd's) required for the nymphal stage were 464.36; 422.08; 318.22; 298.25; 216.60 (dd's) at $15^{\circ} \mathrm{C} ; 20$ ${ }^{\circ} \mathrm{C}, 25^{\circ} \mathrm{C}, 30^{\circ} \mathrm{C}$ and $35^{\circ} \mathrm{C}$ respectively. the thermal units expressed as degree-days (dd's) required for incubation period were $917.29 ; 812.49 ; 664.27 ; 465.29$ and 369.24 (dd's) at $15^{\circ} \mathrm{C} ; 20^{\circ} \mathrm{C}, 25^{\circ} \mathrm{C}, 30^{\circ} \mathrm{C}$ and $35^{\circ} \mathrm{C}$ respectively. The thermal units required for various development recorded 1387.36; 1324.83; 1222.98; 954.89 and 652.50 (dd's) at $15^{\circ} \mathrm{C}, 20^{\circ} \mathrm{C}, 25^{\circ} \mathrm{C}, 30^{\circ} \mathrm{C} 35$ respectively.
\end{abstract}

Keyword: Aphis craccivora Koch., Nezara viridula (L.), Developmental rate, Heat requirements (dd's).

\section{INTRODUCTION}

Sine insects are cold blooded animals, temperature plays a major role in their growth and development. There is threshold temperature for each insect. No development occurs when temperatures are below that level. Insects have an optimum temperature range in which they will grow rapidly. Then, there is maximum temperature above which development stops. These values can be used in predicting insect activity and appearance of symptoms during the growing season. Each developmental stage of an organism has its own total heat requirements. Development can be estimated by accumulating 
degree-days between the maximum and minimum temperature throughout the season (Abd El-Galil et al.1986).

Each species requires defined number of degree-days to complete its development. The data to begin accumulating degree-days that known as the biofix date varies with the species. Biofix points are usually based on some specific events such as first trap catch or first occurrence of the pest. Once the biofix point is established, the degree- days can be accumulated. Degreedays will allow for predicting pest occurrence and used as a tool for scheduling sprays and beneficial insect releases at the optimum time to obtain best results, to monitor pest activity and to determe the best sampling times (Fletcher 1989).

Temperature controls the developmental rate of many organisms, plants and invertebrate animals, including insects and nematodes require certain amounts of heat to develop from one point in their life cycles to another. This measure of accumulated heat is known as degree-days. Growth and development of insect is dependent on temperature where the temperature increase, development time decreases until the temperature becomes high enough to have a negative effect. This limit is define as "temperature threshold ". The lower development threshold for a species is the minimum temperature at which development can begin. The upper developmental threshold is the temperature at which the rate of development creases to increase and begins to decrease. Each insect species has its own particular developmental rate. So, degree- days (which also referred as growing degree-days, i.e. heat units or thermal units) can be defined as the units combining the time and temperature, used to measure the development of an organism from one point to another in its life cycle. (Baskerville and Emin, 1969; Wilson and Barnett, 1983 and Zalom et al. 1983).

Numerous entomologists in different parts of the world recorded the piercing- sucking insects infesting cowpea crop (Hamid et al., 1977; Ali et al., 1979; Berg 1984; Clolazz et al.1986 and Abd El-Galil et al. 1986).

Development rates of some piercing-sucking insects have been investigated by several investigator in different parts of the world (Kocourek and Brankova, 1989; Wang and Tsai, 1996; Adam, 1998; Uygum and Atlhan,2000; Omkar and Pervez, 2004; Davis et al. 2006; Ohta, 2012 and Abd El-Wahab, 2014).

Therefore the present investigation aimed to study some ecological and biological aspects of certain piercing-sucking insects under different constant temperature degrees as an aim for limiting heat unit requirement that necessary for the development of different stages to complete one generation, as well helping in the design of developmental indexes used for determining the time required for these stage under fluctuating temperature in the field.

\section{MATERIALS AND METHODS}

The experiments were carried out in the laboratory of Economic Entomology Department of the Faculty of Agriculture, Mansoura University to estimate the heat requirements as a tool for predicting the annual generation 
of some piercing - sucking insects infesting cowpea plantations at Mansoura district. The cowpea variety was Giza 3. An area of about $1 / 4$ feddan was used for this study. The plants received the normal agricultural practices without insecticidal treatments. The biological studies were conducted in the laboratory of Economic Entomology Department , Faculty of Agriculture, Mansoura University.

\section{1-Rearing of Aphis craccivora :-}

The experimental insects of $A$. craccivora were obtained from the stock culture, maintained under the laboratory conditions. In order to estimate the nymphal duration twenty first nymphal instar were placed separately on cowpea leaves into Petri-dishes $(10 \mathrm{~cm}$ in diameter) at each of the fore mentioned temperatures. The nymphals were examined to determine molt and mortality and the cowpea leaves were replaced daily. The duration period of the nymphal stage was calculated. The longevity and fecundity of adult stage were estimated.

\section{2- Rearing of Nezara viridula}

A culture of the Nezara viridula was started using adults collected from the cowpea plants in farm of the Agriculture Research Center of Faculty of Agriculture, Mansoura university. The culture was maintained under laboratory condition on cowpea leaves into plastic containers $(10 \times 20 \mathrm{~cm})$. Cowpea leaves were supplied to serve as diet and opiposition substrate.

For investigate some biological aspects of $N$. viridula, experiment was carried out to study the effected constant temperatures of $15 \pm 1,20 \pm 1$, $25 \pm 1,30 \pm 1$ and $35 \pm 1 \mathrm{C}^{\circ}$ on the development of egg, nymphal and adult stages of the insect pest. The experimental insects of the $N$. viridula were obtained from the stock culture, maintained under the laboratory conditions. About 500 eggs in five replicates (100 eggs) were used to determine the incubation period in each temperature regimes. Eggs were examined daily and the number of hatched eggs were recorded and the incubation period was calculated.

In order to estimate the nymphal duration 20 newly emerged nymphs were placed separately on cowpea leaves into plastic containers $(10 \times 20 \mathrm{~cm})$ at each of the aforementioned temperatures. The upper rim of the container was covered with mesh screen and fixed with a rubber band. The nymphs were examined to determine moult and mortality and the cowpea leaves were replaced daily. The duration period of nymphal stage was estimated. To study the effect of constant temperatures on the reproductive potential of the adults, eggs and nymphs were allowed to develop in the previously mentioned temperature regimes to reach adult stage. Pairs of newly emerged male and female each were confined separately in a plastic containers $(10 \times 20 \mathrm{~cm})$.

\section{Statistical analysis:}

Data were analyzed by the analysis variance (ANOVA) and Duncan multiple range.

Degree- days "DDS" were calculated using linear regression method as follows.

1. The thermal units (DDS) required for development of each stage were calculated as Fletcher (1989) equation:

$$
\mathrm{K}=\mathrm{y}(\mathrm{X}-\mathrm{t})
$$


Whereas $\mathrm{K}$ represents degree days

$Y$ represents stage duration (in days)

$X$ represents temperature $\left(C^{\circ}\right)$ during development

And $t$ represents the lowers development threshold.

2. The lower development threshold (to) were determined according to linear regression method as the following:

A: The points obtained when the reciprocal for time in days multiplied by $100(1 / t \times 100-$ rate of development- are plotted against temperatures $(T)$ in degree centigrade, the distribution of the points indicates the course of temperature - velocity curve ( Davidson, 1944). The average percentage values of development in one day which are presented within normal zone of development are fitted to straight line (Regression line).

B. The erotically, the point which the velocity line crosses the temperature axis the threshold (to) of development in degree centigrade. This step obtained by applying the straight line equation:

$Y=a+b x$

Whereas y represented y- coordinate (Rate of development)

a represents y-intercept.

$b$ represents slope of the line

and $x$ represents log of $x$ - coordinate (Temperatures).

\section{RESULTS AND DISCUSSION}

Thermal requirements of some piercing-sucking insects infesting cowpea plants for development under constant temperatures degrees:

1: A. craccivora

A: Nymphal stage

Data represented in Table (1 and 2) showed that the required time for developing nymphal instars of $A$. craccivora when reared on cowpea plants decreased as the temperature degrees increased. The mean periods of nymphal instars were $13 \pm 0.79$ days; $8.6 \pm 0.77$ days; $4.9 \pm 0.65$ days and $4.5 \pm 0.88$ days and $4.2 \pm 0.1$ days at $15,20,25,30,35{ }^{\circ} \mathrm{C}$. The relation between developmental rate $(1 / \mathrm{d})$ and the temperature degrees showed that the rate of development declined as temperature increased with significant differences between developmental rates for $A$. craccivora. The regression line of this relation is a remarkable good fit to calculate the temperature velocity line for detecting statistically the lower development threshold (to) for this nymphal stage. The lower development threshold for this stage was7.69 the thermal units, expressed as degree-days (dd's) required for nymphal stage was 118.30 at temperature of $15{ }^{\circ} \mathrm{C}$ degrees. It is apparent that increasing of temperature was accompanied with fasten developmental rate $\left(7.69,11.63,16.95,20.41\right.$ and 23.81 at $15^{\circ} \mathrm{C}, 20^{\circ} \mathrm{C}, 25^{\circ} \mathrm{C}, 30^{\circ} \mathrm{C}$ and $35^{\circ} \mathrm{C}$ respectively). The thermal units required for ovaries development recorded 118.30, 121.26, 112.69,118.09 and 122.22 degree-days (dd's) at $15^{\circ} \mathrm{C}, 20^{\circ} \mathrm{C}, 25^{\circ} \mathrm{C}, 30^{\circ} \mathrm{C}$ and $35^{\circ} \mathrm{C}$ respectively, as calculated by thermal summation equation $\mathrm{K}=\mathrm{y}(\mathrm{x}-\mathrm{to})$. 


\section{B: Adult stage}

Longevity shown in (Table 3 and 4 ) and illustrated in (Fig1) cleared that the lower threshold of development was $15^{\circ} \mathrm{C}$. It is apparent that increasing of temperature was accompanied with fasten developmental rate $(7.52,9.43$, $10.64,11.91$ and 13.89 at $15^{\circ} \mathrm{C}, 20^{\circ} \mathrm{C}, 25^{\circ} \mathrm{C}, 30^{\circ} \mathrm{C}$ and $35^{\circ} \mathrm{C}$ respectively). The thermal units required for ovaries development recorded 127.68, 154.76, 184.24, 206.64 and 213.12 degree-days (dd's) at $15{ }^{\circ} \mathrm{C}, 20^{\circ} \mathrm{C}, 25^{\circ} \mathrm{C}, 30^{\circ} \mathrm{C}$ and $35^{\circ} \mathrm{C}$ respectively, as calculated by thermal summation equation $\mathrm{K}=\mathrm{y}(\mathrm{x}-$ t0 ). The longest reproductive period $8.3 \pm 0.83$ days was obtained at $15^{0} \mathrm{C}$. While the shortest one $5.2 \pm 0.42$ was attained at $35^{\circ} \mathrm{C}$.

Table (1). Developmental time in days of nymphal instars of $A$. craccivora when reared on cowpea plants under different temperature degrees.

\begin{tabular}{|c|c|c|c|c|c|c|}
\hline stages & Temp. & \multicolumn{4}{|c|}{ Nymphal instars } & \multirow{2}{*}{ Total in days } \\
\cline { 3 - 7 } & & $\mathbf{1}$ & $\mathbf{2}$ & $\mathbf{3}$ & $\mathbf{4}$ & \\
\cline { 2 - 7 } $\begin{array}{c}\text { A: } \\
\text { Nymphal } \\
\text { stage }\end{array}$ & $\mathbf{1 5}$ & $3.3 \pm 0.82$ & $3.3 \pm 0.82$ & $3.2 \pm 0.76$ & $3.2 \pm 0.65$ & $13 \pm 0.79$ \\
\cline { 2 - 7 } & $\mathbf{2 0}$ & $2.1 \pm 0.76$ & $2.2 \pm 0.79$ & $2.1 \pm 0.76$ & $2.2 \pm 0.82$ & $8.6 \pm 0.77$ \\
\cline { 2 - 7 } & $\mathbf{2 5}$ & $1.3 \pm 0.71$ & $1.2 \pm 0.76$ & $1.2 \pm 0.79$ & $1.2 \pm 0.81$ & $4.9 \pm 0.65$ \\
\cline { 2 - 7 } & $\mathbf{3 0}$ & $1.1 \pm 0.82$ & $1.1 \pm 0.82$ & $1.3 \pm 0.88$ & $1.0 \pm 0.74$ & $4.5 \pm 0.88$ \\
\cline { 2 - 7 } & $\mathbf{3 5}$ & $1.0 \pm 0.34$ & $1.0 \pm 0.66$ & $1.2 \pm 0.34$ & $1.0 \pm 0.44$ & $4.2 \pm 0.1$ \\
\hline
\end{tabular}

Table (2). Developmental rate in days and thermal units(DD's) of nymphal instars of $A$. craccivora when reared on cowpea plants under different temperature degrees.

\begin{tabular}{|c|c|c|c|c|}
\hline Stages & Temp. & $\begin{array}{c}\text { Duration (days) } \\
\text { mean } \pm \text { S.E. }\end{array}$ & $\begin{array}{l}\text { Developmental } \\
\text { rate }\end{array}$ & $\begin{array}{c}\text { Thermal units } \\
\text { (DD's) }\end{array}$ \\
\hline \multirow{5}{*}{ 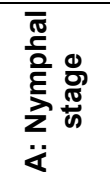 } & 15 & $13.0 \pm 0.79$ & 7.69 & 118.30 \\
\hline & 20 & $8.6 \pm 0.77$ & 11.63 & 121.26 \\
\hline & 25 & $5.9 \pm 0.65$ & 16.95 & 112.69 \\
\hline & 30 & $4.9 \pm 0.88$ & 20.41 & 118.09 \\
\hline & 35 & $4.2 \pm 0.1$ & 23.81 & 122.22 \\
\hline
\end{tabular}

Table (3). Developmental time in days of Adult stage of $\boldsymbol{A}$. craccivora when reared on cowpea plants under different temperature degrees.

\begin{tabular}{|c|c|c|c|c|c|}
\hline \multirow{7}{*}{$\begin{array}{c}\text { B: } \\
\text { Adult } \\
\text { stage }\end{array}$} & \multirow[t]{2}{*}{ Temp. } & \multicolumn{3}{|c|}{ Longevity } & \multirow[b]{2}{*}{$\begin{array}{c}\text { Total in } \\
\text { days }\end{array}$} \\
\hline & & $\begin{array}{c}\text { Pre-reproductive } \\
\text { period }\end{array}$ & $\begin{array}{l}\text { reproductive } \\
\text { period }\end{array}$ & $\begin{array}{c}\text { Post- reproductive } \\
\text { period }\end{array}$ & \\
\hline & 15 & $2.7 \pm 0.83$ & $8.3 \pm 0.83$ & $2.3 \pm 0.91$ & $13.3 \pm 0.91$ \\
\hline & 20 & $2.2 \pm 0.81$ & $6.8 \pm 0.79$ & $1.5 \pm 0.89$ & $10.6 \pm 0.89$ \\
\hline & 25 & $1.2 \pm 0.79$ & $6.8 \pm 0.81$ & $1.4 \pm 0.85$ & $9.4 \pm 0.93$ \\
\hline & 30 & $1.0 \pm 0.60$ & $6.2 \pm 0.93$ & $1.2 \pm 0.79$ & $8.4 \pm 0.62$ \\
\hline & 35 & $1.0 \pm 0.30$ & $5.2 \pm 0.42$ & $1.0 \pm 0.83$ & $7.2 \pm 0.84$ \\
\hline
\end{tabular}

These results are in agreement with those results of Ohta (2012), he found that Apterous viviparous nymphs and adults of $M$. persica were kept at constant temperatures of $15^{\circ} \mathrm{C}, 20^{\circ} \mathrm{C}, 25^{\circ} \mathrm{C}$ and $30^{\circ} \mathrm{C}$ the mean developmental times from first instar to adult emergence decreased as the temperature increased. 
Table (4). Longevity periods in days and thermal units(DD's) of Adult stage of $A$. craccivora when reared on cowpea plants under different temperature degrees.

\begin{tabular}{|c|c|c|c|c|}
\hline & Temp. & \multicolumn{3}{|c|}{ Longevity } \\
\hline \multirow{6}{*}{ 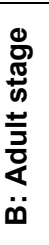 } & & $\begin{array}{c}\text { Duration (days) } \\
\text { mean } \pm \text { S.E. }\end{array}$ & $\begin{array}{c}\text { Developmental } \\
\text { rate }\end{array}$ & $\begin{array}{c}\text { Thermal units } \\
\text { (DD's) }\end{array}$ \\
\hline & 15 & $13.3 \pm 0.91$ & 7.52 & 127.68 \\
\hline & 20 & $10.6 \pm 0.89$ & 9.43 & 154.76 \\
\hline & 25 & $9.4 \pm 0.93$ & 10.64 & 184.24 \\
\hline & 30 & $8.4 \pm 0.62$ & 11.91 & 206.64 \\
\hline & 35 & $7.2 \pm 0.84$ & 13.89 & 213.12 \\
\hline
\end{tabular}
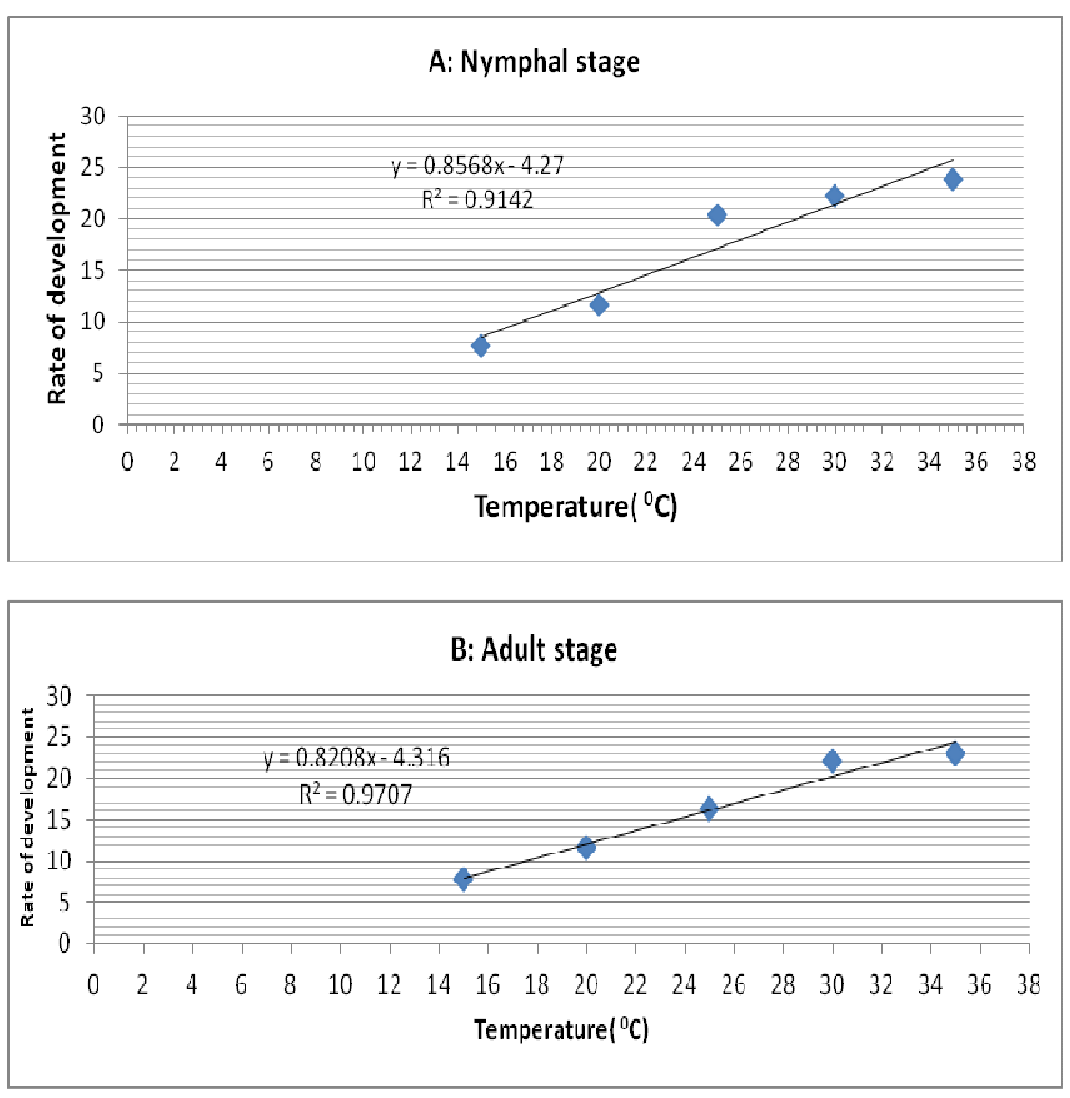

Figure (1): Developmental rates of Nymphal stage and adult stage of $A$. craccivora when reared on cowpea plants at various temperature regimes, Parallel line analysis was done to test for equality of regression slopes. 


\section{2- N. viridula \\ A: Egg stage}

The required time for completion of embryogenesis decreased as the temperature increased when this insect reared on cowpea plants. The mean period of egg incubation was 5.0, 5.4, 7.0,6.4 and 6.3days at 15, 20, 25, 30 and $35^{\circ} \mathrm{C}$, respectively. The relation between developmental rate $(1 / \mathrm{d})$ and the five tested temperature degrees showed that the rate of development was slower at $15^{\circ} \mathrm{C}$ than at the other temperatures. The regression line of this relation is a remarkable good fit to calculate the temperature velocity line for detecting statistically the lower development threshold (to) for this stage and it was $35^{\circ} \mathrm{C}$ when reared on cowpea plants. The thermal units, expressed as degree-days (DD's), required for egg stage on cowpea plants were 917.29, $812.49,664.27,465.29$ and 369.24 (dd's) at $15,20,25,30$ and $35{ }^{\circ} \mathrm{C}$ respectively (Table5).

\section{B: Nymphal stage}

The required time for developing nymphal instars of $N$. viridula when reared cowpea plants decreased ad the temperature degrees increased. The mean periods of nymphal instars were $34.1,37.1,38.3,39.1$ and 39.6 days at $15,20,25,30,35{ }^{\circ} \mathrm{C}$ (Table 5, 6 and 7). The relation between developmental rate $(1 / d)$ and the temperature degrees showed that the rate of development declined as temperature increased with significant differences between developmental rates for $N$. viridula. The regression line of this relation is a remarkable good fit to calculate the temperature velocity line for detecting statistically the lower development threshold (To) for this nymphal stage. The lower development threshold for this stage was 216.60 the thermal units, expressed as degree-days (dd's) required for nymphal stage was 465.36.

\section{C: Adult stage}

Pre-oviposition period shown in Table (8 and 9 ) and illustrated in Fig. ( 2 ) revealed that the lower threshold of development was $15^{\circ} \mathrm{C}$. It is apparent that increasing of temperature was accompanied with fasten developmental rate of female ovaries $3.57,2.57,2.48,2.34$ and 1.34 at $15^{\circ} \mathrm{C}$, $20^{\circ} \mathrm{C}, 25^{\circ} \mathrm{C}, 30^{\circ} \mathrm{C}$ and $35^{\circ} \mathrm{C}$ respectively. Fertilized female continued to lay eggs within a period varied from 48.34 to 75.0 according to the temperature (Table

and9 ). The longest oviposition period 37.2 days was obtained at $35^{\circ} \mathrm{C}$. While the shortest one 20.31 days was attained at $15^{\circ} \mathrm{C}$. Data also illustrated that oviposition periods of $N$. viridula fertilized females were significantly affected with evaluated constant temperatures. The fecundity (total number of eggs produced per fertilized female) ranged from 266.0 to 104.6 at different constant temperatures. Statistically, highly significant differences were obtained between the mean fecundity of females at different temperatures. Significantly, more eggs were laid at $35^{\circ} \mathrm{C}$ (266.2 eggs). These results are in practical agreement with those of Darwish et al.(2000), they the threshold temperature of 10.52 degrees, 4.59 degrees and 7.06 degrees were calculated for the development of egg, nymph and from egg to adult stage, respectively. 
Table (5). Developmental time in days of immature stages of $\boldsymbol{N}$. viridula when reared on cowpea plants under different temperatures.

\begin{tabular}{|c|c|c|c|c|c|c|c|}
\hline \multirow{2}{*}{ Temp. } & \multicolumn{5}{|c|}{ Immature stages } & \multirow{2}{*}{ Total days } \\
\cline { 2 - 6 } & $\mathbf{e g g}$ & $\mathbf{1}^{\text {th }}$ & $\mathbf{2}^{\text {nd }}$ & $\mathbf{3}^{\text {rd }}$ & $\mathbf{4}^{\text {th }}$ & $\mathbf{5}^{\text {th }}$ & \\
\hline $\mathbf{1 5}$ & $5.0 \pm 0.17$ & $5.8 \pm 0.30$ & $5.0 \pm 0.07$ & $4.0 \pm 0.02$ & $5.1 \pm 0.10$ & $9.2 \pm 0.04$ & $34.1 \pm 0.12$ \\
\hline $\mathbf{2 0}$ & $5.4 \pm 0.09$ & $6.0 \pm 0.70$ & $5.3 \pm 0.03$ & $4.8 \pm 0.80$ & $5.2 \pm 0.08$ & $9.6 \pm 0.15$ & $37.1 \pm 0.28$ \\
\hline $\mathbf{2 5}$ & $6.3 \pm 0.80$ & $6.4 \pm 0.80$ & $5.5 \pm 0.05$ & $4.9 \pm 0.06$ & $5.9 \pm 0.13$ & $9.4 \pm 0.11$ & $38.3 \pm 0.16$ \\
\hline $\mathbf{3 0}$ & $6.4 \pm 0.19$ & $6.7 \pm 0.80$ & $5.4 \pm 0.05$ & $5.1 \pm 0.07$ & $6.1 \pm 0.20$ & $8.6 \pm 0.10$ & $39.1 \pm 0.34$ \\
\hline $\mathbf{3 5}$ & $7.0 \pm 0.13$ & $7.2 \pm 0.82$ & $5.6 \pm 0.05$ & $5.1 \pm 0.51$ & $6.3 \pm 0.12$ & $9.9 \pm 0.13$ & $39.6 \pm 0.14$ \\
\hline
\end{tabular}

Table (6): Developmental rate in days and thermal units(DD's) of incubation period $\boldsymbol{N}$. viridula when reared on cowpea plants at different temperatures.

\begin{tabular}{|c|c|c|c|}
\hline \multirow{2}{*}{ Temp. } & \multicolumn{3}{|c|}{ Incubation period } \\
\cline { 2 - 4 } & Duration (days) & Developmental rate & $\begin{array}{c}\text { Thermal units } \\
\text { (DD's) }\end{array}$ \\
\cline { 2 - 4 } & mean \pm S.E. & 2.93 & 917.29 \\
\hline $\mathbf{1 5}$ & $34.1 \pm 0.12$ & 2.70 & 812.49 \\
\hline $\mathbf{2 0}$ & $37.1 \pm 0.28$ & 2.61 & 664.27 \\
\hline $\mathbf{3 0}$ & $38.3 \pm 0.16$ & 2.56 & 465.29 \\
\hline $\mathbf{3 5}$ & $39.1 \pm 0.34$ & 2.53 & 369.24 \\
\hline
\end{tabular}

Table (7): Developmental rate in days and thermal units(DD's) of nymphal stage $N$. viridula when reared on cowpea plants at different temperature degrees.

\begin{tabular}{|c|c|c|c|}
\hline \multirow{2}{*}{ Temp. } & \multicolumn{3}{|c|}{ Nymphal stages } \\
\cline { 2 - 4 } & $\begin{array}{c}\text { Duration (days) } \\
\text { mean } \pm \text { S.E. }\end{array}$ & $\begin{array}{c}\text { Thermal units } \\
\text { (DD's) }\end{array}$ \\
\hline $\mathbf{1 5}$ & 29.1 & 1.20 & 465.36 \\
\hline $\mathbf{2 0}$ & 30.9 & 2.28 & 422.08 \\
\hline $\mathbf{2 5}$ & 32.1 & 2.30 & 318.22 \\
\hline $\mathbf{3 0}$ & 31.9 & 2.40 & 298.25 \\
\hline $\mathbf{3 5}$ & 34.1 & 2.90 & 216.60 \\
\hline
\end{tabular}

Table (8). Longevity periods in days of Adult stages of $\boldsymbol{N}$. viridula when reared on cowpea plants at different temperatures degrees.

\begin{tabular}{|c|c|c|c|c|c|c|}
\hline \multirow{2}{*}{ Temp. } & \multirow{2}{*}{$\begin{array}{c}\text { Pre- } \\
\text { ovipositon }\end{array}$} & Oviposition & \multirow{2}{*}{$\begin{array}{c}\text { Post- } \\
\text { ovipositon }\end{array}$} & \multirow{2}{*}{$\begin{array}{c}\text { Number of } \\
\text { eggs/female }\end{array}$} & \multicolumn{2}{|c|}{ longevity } \\
\cline { 6 - 7 } & & & & & Male & Female \\
\hline $\mathbf{1 5}$ & $14.2 \pm 1.20$ & $20.31 \pm 2.42$ & $13.83 \pm 1.99$ & $104.6 \pm 27.09$ & $22 \pm 2.38$ & $48.34 \pm 4.24$ \\
\hline $\mathbf{2 0}$ & $15.3 \pm 1.18$ & $22.3 \pm 2.25$ & $18.3 \pm 1.37$ & $111.4 \pm 35.56$ & $25.8 \pm 3.63$ & $55.9 \pm 5.28$ \\
\hline $\mathbf{2 5}$ & $15.4 \pm 0.90$ & $29.0 \pm 2.25$ & $18.4 \pm 2.11$ & $130 \pm 25.03$ & $35.3 \pm 4.32$ & $65.4 \pm 3.75$ \\
\hline $\mathbf{3 0}$ & $18.0 \pm 1.83$ & $29.0 \pm 2.37$ & $20.4 \pm 2.53$ & $156.6 \pm 36.24$ & $38.5 \pm 5.10$ & $69.7 \pm 7.87$ \\
\hline $\mathbf{3 5}$ & $20.3 \pm 2.02$ & $37.2 \pm 5.11$ & $22.4 \pm 1.35$ & $266.0 \pm 62.47$ & $68.0 \pm 4.54$ & $75.0 \pm 5.56$ \\
\hline
\end{tabular}


Table (9): Developmental rate in days and thermal units(DD's) of $N$. viridula adult when reared on cowpea plants at different temperatures degrees.

\begin{tabular}{|c|c|c|c|}
\hline \multirow[t]{2}{*}{ Temp. } & \multicolumn{3}{|c|}{ Longevity } \\
\hline & $\begin{array}{l}\text { Duration (days) } \\
\text { mean } \pm \text { S.E. }\end{array}$ & $\begin{array}{c}\text { Developmental } \\
\text { rate }\end{array}$ & $\begin{array}{c}\text { Thermal units } \\
\text { (DD's) }\end{array}$ \\
\hline 15 & $48.34 \pm 4.24$ & 3.57 & 1387.36 \\
\hline 20 & $55.9 \pm 5.28$ & 2.57 & 1324.83 \\
\hline 25 & $65.4 \pm 3.75$ & 2.48 & 1222.98 \\
\hline 30 & $69.7 \pm 7.87$ & 2.34 & 954.89 \\
\hline 35 & $75.0 \pm 5.56$ & 1.34 & 652.50 \\
\hline
\end{tabular}

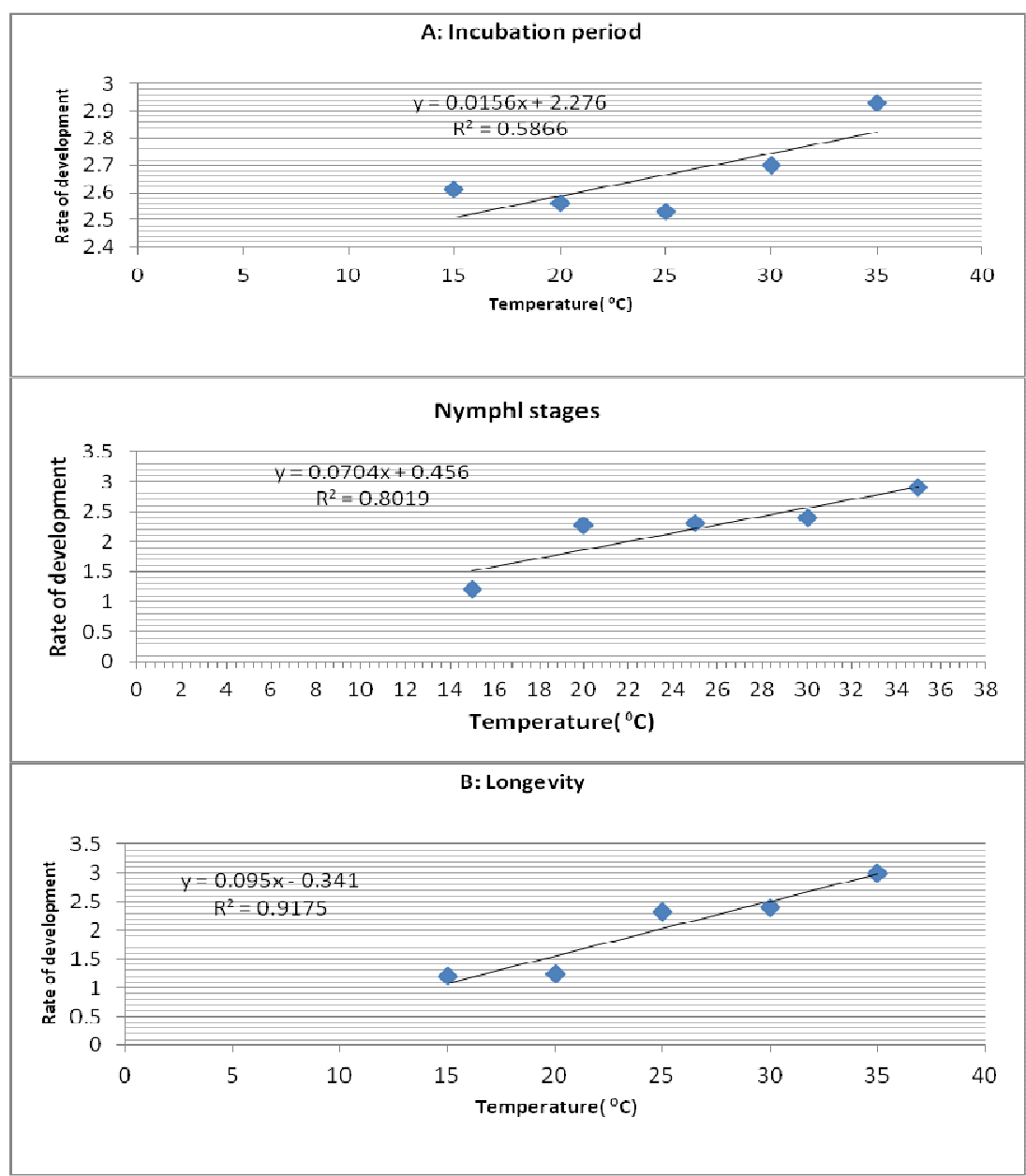

Figure (2): Developmental rates of incubation period, nymphal stages and longevity of $\boldsymbol{N}$. viridula when reared cowpea plants at various temperature regimes, Parallel line analysis was done to test for equality of regression slopes. 


\section{REFERENCES}

Abd El-Galil, A.A., Darwish, Y.A. and Mosftah, E.A. (1986). Activity of the cowpe aphid, Aphis craccivora and predation prey efficiency of Coccinella undecimpunctata L. (Coleoptera: Coccinellidae). J. Agric. Sci. Assiut, 17(1) 41-50.

Abd El-Wahab, A.H. (2014). Ecological and biological studies on Bemisia tabaci biotypes complex and their natural enemies. M.Sc. Thesis, Faculty of Agric. Mansoura University.

Adam, K. M. (1998). Studies on the effect of threshold temperatures, degreeday estimates on certain population growth parameters of the cotton aphid, Aphis gossypii (Glover) infesting watermelon in Upper Egypt. Egyptian J. Agric. Res.; 76( 3) 961-968.

Ali, M.A.; Awadallah, A.M. and El-Rahamen, A.A. (1979). A study on the phonology and ecology of the green stink bug Nezara viridula (Hemiptera: Pentatomidae). Zeit.Ang. Ent. 88:476-483.

Baskerville, G.L. and Emin, P. (1969). Rapid estimation of heat accumulation from maximum and minimum temperature. Ecology, 50(3): 514-517.

Berg, G.N. (1984). The effect of temperature and host species on the population growth potential of the cowpea aphid, Aphis craccivora Koch (Homoptera: Aphiaidae). Australian J. Zool. 32(3): 345-352.

Collazza, S. E.; Ciriciofolo, B.L. and Bin. F. (1986). Nezara viridula(L.) injurious to soybean in central Italy (Hemiptera: Pentatomidae). Informate Agric. 42(3/4)79-84.

Darwish, Y. A.; Mannaa, S. H. and Abdel-Rahman, M. A. A. (2000). Effect of constant temperatures on the development of egg and nymphal stages of the cotton whitefly, Bemisia tabaci (Genn.) (Homoptera: Aleyrodidae), and use of thermal requirements in determining its annual generation numbers. Assiut J. Agric. Sci. ;31(1)207-216.

Davidson J. 1944. On the relationship between temperature and rate of development of insects at constant temperatures. Journal of Animal Ecology 13: 26-38.

Davis, J. A.; Radcliffe, E. B. and Ragsdale, D. W. (2006). Effects of high and fluctuating temperatures on Myzus persicae (Hemiptera: Aphididae).Environmental Entomology; 35 (6) 1461-1468.

Fletcher, B., S. (1989). Temperature-development rate relationships of the immature stages and adults of tephritid fruit flies. (Robinson, A. S. and Hooper, G. (Eds) Fruit Flies, their biology, natural enemies and Control. World Crop Pests 3B, Amsterdam, Elsevier:16 pp).

Hamid, S.; Shah, H.A. and Anwar, A.M. (1977). Some ecological behavioral studies on Aphis craccivora Kock (Homoptera: Aphididae). Technical Bulletin Common weath Institute of Biological control. 18:99-111.

Kocourek, F. and Berankova, J. (1989). Temperature requirements for development and population growth of the green peach aphid Myzus persicae on sugar beet. Acta Entomologica Bohemoslovaca; 86( 5)349355. 19 ref. 
Ohta, I. (2012). Practical evaluation of an indigenous aphid parasitoid, Aphidius gifuensis (Hymenoptera, Braconidae) as a biological control agent against green peach aphid, Myzus persicae (Heteroptera, Aphididae) and its effective applications in greenhouses [Japanese]. Bulletin of the National Institute of Vegetable and Tea Science;. 11: 133.

Omkar, A. and Pervez, A. (2004). Temperature-dependent development and immature survival of an aphidophagous ladybeetle, Propylea dissecta (Mulsant). J. of Appl. Ent.; 128: (7) 510-514.

Uygun, N. and Atlhan, R. (2000). The effect of temperature on development and fecundity of Scymnus levaillanti. BioControl;. 45: (4) 453-462.

Wang and Tsai, J. H. (1996). Temperature effect on development and reproduction of silverleaf whitefly (Homoptera: Aleyrodidae). Annals Entomol. Soci. of America. 89( 3) 375-384.

Willson, L.T. and Barnett, W.W.(1983). Degree-days: an aid in crop and pest management. California Agric., 37:4-7.

Zalom, F. G., Goodell, P.B.; Wilson, L.T., Brnett, W.W. and Bentley, W.J. (1983). Degree- days, the calculation and use of heat units in pest management. University of California Division of Agriculture and Natural Resources Leaflet 21373. Cited in htt://www.ipm.ucdavis.edu/weather/ddconcepts.html.

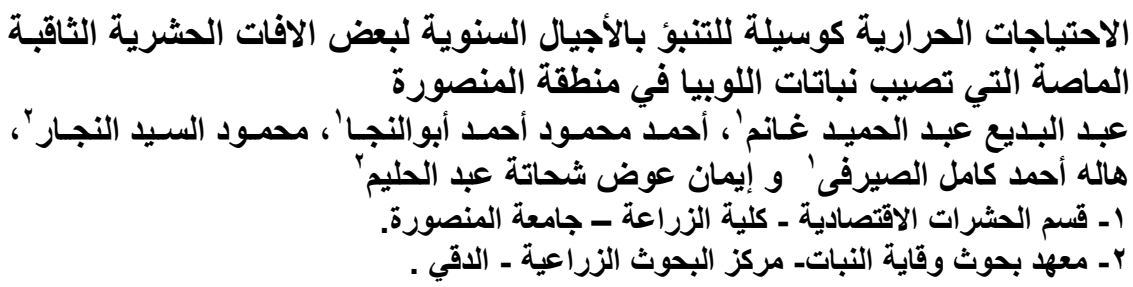

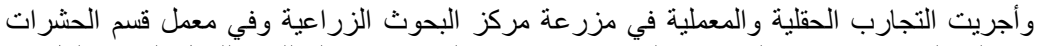

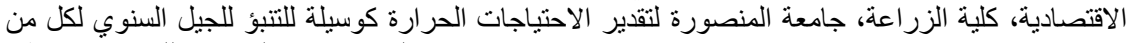
Nezara viridula (L.) و Aphis craccivora Koch.

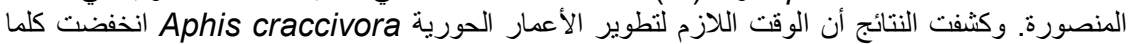

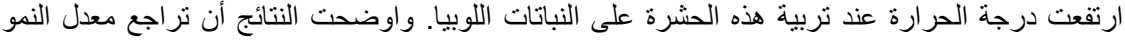

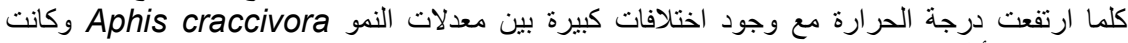

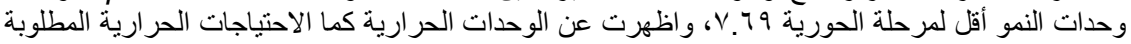

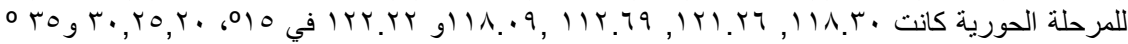

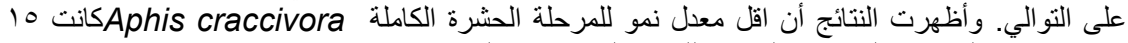

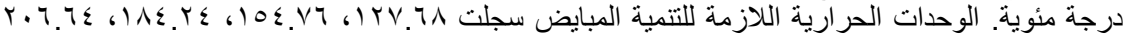

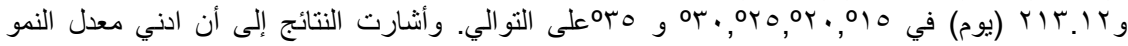
Nezara viridula

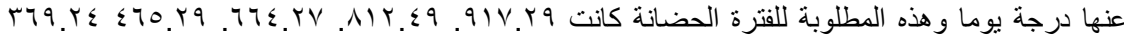

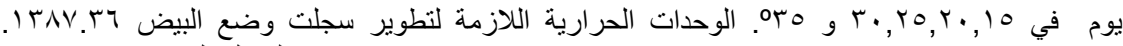

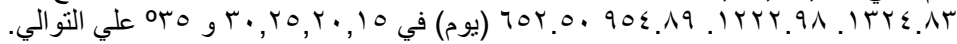

